\title{
Livros didáticos e formação de professores que ensinam Matemática nos anos iniciais do Ensino Fundamental ${ }^{1}$
}

\section{Mathematics textbooks and continuing education for teachers who teach mathematics in elementary school}

\author{
Gláucia Marcondes Vieira ${ }^{2}$ \\ Maria Laura Magalhães Gomes ${ }^{3}$
}

\begin{abstract}
RESUMO
Este artigo apresenta alguns resultados de uma pesquisa sobre a utilização de livros didáticos de Matemática por professores dos anos iniciais do Ensino Fundamental. O material empírico da investigação é constituído pelas entrevistas de dez professores de escolas públicas e privadas da região metropolitana de Belo Horizonte, com o uso da metodologia da História Oral. O foco do artigo é o papel desempenhado pelos livros didáticos para a formação dos docentes para as práticas pedagógicas relacionadas aos conhecimentos matemáticos. Nas narrativas dos docentes, destacam-se as críticas ao manual do professor, o reconhecimento do livro didático como um elemento importante, embora não único, no desenvolvimento curricular, e as afirmações dos próprios saberes dos professores quanto a seus alunos e realidades escolares.
\end{abstract}

Palavras-chave: livros didáticos de Matemática; anos iniciais do Ensino Fundamental; narrativas de professores; formação de professores que ensinam Matemática.

DOI: $10.1590 / 0104-4060.34325$

1 Instituição financiadora da pesquisa: FAPEMIG - Fundação de Amparo à Pesquisa do Estado de Minas Gerais.

2 Universidade Estadual de Minas Gerais, Departamento de Métodos e Técnicas de Ensino. Belo Horizonte, Minas Gerais, Brasil. Rua Paraíba, 29, Funcionários. CEP: 30130-140.

3 Universidade Federal de Minas Gerais, Departamento de Matemática e Programa de Pós-Graduação em Educação. Belo Horizonte, Minas Gerais, Brasil. Avenida Antônio Carlos 6627, Pampulha. CEP: 31270-901. 


\begin{abstract}
This article presents some results of a research on the use of mathematics textbooks by elementary school teachers. The empirical material consists of interviews of ten teachers from public and private schools in the metropolitan region of Belo Horizonte, using the methodology of oral history. The focus of the article is the role of textbooks for the education of teachers for pedagogical practices related to mathematical knowledge. The teachers' narratives show criticisms on their manual, recognition of the textbook as an important element, although not exclusive, for curriculum development, and an emphasis on teachers' own knowledge about their students and school realities.
\end{abstract}

Keywords: Mathematics textbooks; early years of elementary school; narratives of teachers; education of teachers who teach mathematics.

\title{
Introdução
}

Documentos atuais referentes à educação brasileira tais como os Parâmetros Curriculares Nacionais (PCNs), o Projeto de Lei do Plano Nacional de Educação (PNE-2011/2020), e o Guia do Livro Didático do Programa Nacional do Livro Didático (PNLD) trazem uma série de considerações a respeito do livro didático como material de apoio à atuação do professor. Em tais documentos e outros, o livro didático é visto como um recurso de grande repercussão nas práticas pedagógicas, capaz de organizar, sintetizar e qualificar a aprendizagem, configurando não somente o que se ensina e se aprende, como também o que se avalia dentro e fora da escola.

No que diz respeito particularmente ao ensino de Matemática nos anos iniciais do Ensino Fundamental, é possível identificar, nas recomendações dos PCNs, atenção específica em relação ao uso do livro didático pelo docente. De fato, salientando o papel importante desse material no processo de ensino-aprendizagem, o texto dos PCNs de Matemática (BRASIL, 1997) reconhece problemas na formação dos professores e recorre a esses problemas como justificativa para o fato de as práticas em sala de aula, em sua maioria, estarem centradas no livro didático. Ao mesmo tempo, o documento alerta para a necessidade de os livros estarem "integrados a situações que levem ao exercício da análise e da reflexão, em última análise, a base da atividade matemática" (BRASIL, 1997, p. 22), ressaltando que os professores precisam desenvolver maior autonomia. 
Apesar de não ter havido, até o presente momento, uma proposta curricular nacional posterior aos PCNs, estados e municípios vêm produzindo e estabelecendo seus próprios projetos curriculares desde a publicação do documento de 1997. Por exemplo, em Belo Horizonte, desde 2010 estão em vigor as Proposições Curriculares voltadas aos anos iniciais do Ensino Fundamental, elaboradas pela Secretaria Municipal de Educação de Belo Horizonte. Esse documento confere relevância ao papel do livro didático no ensino de Matemática, mas remete-se também às limitações do livro quando recomenda ao professor promover em sala "situações-problema que explorem a leitura de diversos tipos de texto, para além dos livros didáticos de Matemática" (BELO HORIZONTE, 2010, p. 13).

A distribuição dos livros didáticos a alunos e professores das escolas públicas brasileiras tem sido uma política do governo federal brasileiro efetivada mediante as ações do PNLD, criado em 1985, responsável pela aquisição dos livros solicitados pelos professores entre os aprovados em avaliação prévia por especialistas promovida desde 1996 (MUNAKATA, 2012). Após a realização de cada avaliação, cada edição do PNLD publica o Guia do Livro Didático para todas as disciplinas, visando orientar os professores na escolha dos livros. O Guia do PNLD 2013 referente à Matemática trata das coleções destinadas aos cinco primeiros anos do Ensino Fundamental que foram aprovadas e explicita os critérios utilizados para a avaliação. Ao mesmo tempo que esse documento reconhece a importância da ação docente no momento da escolha dos livros, procura subsidiar essa escolha por meio de recomendações, alertas e caracterizações quanto ao que seria um livro didático de Matemática adequado.

O processo de avaliação pedagógica dos livros didáticos inscritos no PNLD é pautado por alguns critérios eliminatórios comuns a todas as disciplinas curriculares e também por critérios específicos de cada uma. Para a Matemática, os critérios eliminatórios específicos relacionam-se à correção de conceitos e de informações básicas, à adequação didático-metodológica e ao manual do professor.

O Guia do PNLD 2013: Matemática recomenda ao professor elaborar um planejamento dos conteúdos a serem estudados, pois considera que nos livros há, muitas vezes, excessos ou repetições excessivas em relação a alguns conteúdos e até a necessidade de complementação em relação a outros. Aconselha o professor, também, "a ampliar o uso de recursos didáticos, quando necessário, e a ter o cuidado no planejamento para uso do material", bem como alerta o docente no sentido de "contornar as imprecisões em explanações de alguns conteúdos e em atividades propostas" (BRASIL, 2012, p. 20). No que se refere ao manual do professor, o Guia indica que o mesmo apresente unidade por unidade e atividade por atividade: 
objetivos; discussão das escolhas didáticas pertinentes; antecipação dos possíveis caminhos de desenvolvimento do aluno e de suas dificuldades; indicações de modificações da atividade, a fim de que o professor possa melhor adequar a atividade a sua realidade local; auxílio ao professor na sistematização dos conteúdos trabalhados; possíveis estratégias de resolução; indicações sobre a avaliação (BRASIL, 2012, p. 18).

As considerações anteriores evidenciam que as políticas públicas para a educação têm contemplado o livro didático de Matemática para os anos iniciais do Ensino Fundamental como um material importante para as práticas pedagógicas, mas em relação a cujo uso são recomendados cuidados. Reconhecem-se, ainda, fragilidades específicas quanto à Matemática na formação dos professores dessa etapa escolar, que levariam os docentes a centrar seu trabalho no livro didático, e o incentivo a uma maior autonomia dos docentes é acompanhado pelas preocupações relativas ao manual do professor, componente indispensável dos livros no escopo do PNLD.

No campo acadêmico, pesquisas sobre livros didáticos têm focalizado, predominantemente, segundo Rocha e Somoza (2012), a análise de seu conteúdo, tendo havido poucos investimentos das investigações quanto às questões ligadas à recepção dos livros didáticos:

[...] a maioria das investigações permanece centrada no momento da emissão da mensagem ou do discurso presente nos livros, sem avançar sobre o momento da recepção. Assim, permanecem na penumbra os processos de decodificação, interpretação, contestação e apropriação que os alunos realizam, assim como as ações de mediação e transformação dos conteúdos originais que os educadores e as próprias instituições escolares produzem, seja de maneira intencional ou contingente (ROCHA; SOMOZA, 2012, p. 24).

Por que e para que os professores utilizam os livros didáticos de Matemática? Quando e como eles recorrem a esse recurso didático em suas práticas pedagógicas? Existem conflitos na utilização do livro didático de Matemática? Quais são esses conflitos e como os professores lidam com eles? Como os conhecimentos advindos de experiências anteriores dos professores se inter-relacionam com a realidade escolar e com os saberes veiculados pela formação superior quando o livro didático é usado nas práticas docentes? Como professores têm pensado sobre e utilizado o livro didático de Matemática? Como o livro 
colabora no processo de ensino e de aprendizagem dos conteúdos matemáticos? Quais estratégias de utilização do livro contribuem para melhor significação dos conhecimentos matemáticos nele contemplados?

Empreendemos uma pesquisa que procurou contribuir no sentido apontado por Rocha e Somoza, buscando compreender os modos de recepção e apropriação do discurso presente nos livros didáticos de Matemática por docentes dos anos iniciais do Ensino Fundamental. Nosso estudo abordou a mediação, pelos professores, dos processos de interação dos estudantes com o conhecimento matemático veiculado por essas obras. A procura de respostas para as questões anteriores fez emergir, como um aspecto importante da utilização dos livros didáticos pelos professores, um dos papéis que essas publicações desempenham - o de recurso para sua formação -, nos momentos em que se preparam para práticas pedagógicas relacionadas aos conhecimentos matemáticos. Neste artigo, abordamos os resultados de nossa investigação quanto ao uso dos livros didáticos na formação do docente que ensina Matemática, focalizando algumas dimensões da busca, pelo professor, de uma formação específica para o exercício de sua atividade profissional de ensinar Matemática aos estudantes dos anos iniciais do Ensino Fundamental.

\section{Dimensões teórico-metodológicas e procedimentos de pesquisa}

Na busca por compreender práticas de professores dos anos iniciais do Ensino Fundamental em relação ao uso dos livros didáticos de Matemática, optamos por uma modalidade de investigação que "lida e dá atenção às pessoas e às suas ideias, procura fazer sentido de discursos e narrativas que estariam silenciosas" (D’AMBRÓSIO, 2012, p. 21). Orientamo-nos por uma perspectiva qualitativa, tentando alcançar "a compreensão dos comportamentos a partir da perspectiva dos sujeitos da investigação" (BOGDAN; BIKLEN, 1994, p. 16) correlacionada ao contexto do qual esses sujeitos fazem parte. Entendemos com Garnica que as modalidades qualitativas de investigação são, frequentemente, "disparadas por depoimentos, ou seja, são narrativas que, perpassadas por uma hermenêutica, apoiam compreensões, as quais, por sua vez, mostram ou nos permitem atribuir significados aos aspectos do objeto analisado" (GARNICA, 2010, p. 3). Assim, não concebemos uma narrativa como um mero texto escrito ou oral, mas, conforme Silva, Baraldi e Garnica, como "um relato que faz sentido no contexto do argumento que o narrador, culturalmente situado, cria", ou seja, narrativas são "resultados de situações de entrevistas, e focam histórias de professores, 
registram memórias várias, 'falam' do modo como, segundo os depoentes, suas experiências se deram" (SILVA; BARALDI; GARNICA, 2013, p. 3).

Diante do reconhecimento das potencialidades das narrativas orais, tomamos como base de nossa investigação narrativas de professores dos anos iniciais do Ensino Fundamental em entrevistas, na tentativa de compreender aspectos que repercutem de forma clara ou implícita nos usos dos livros didáticos de Matemática. Trabalhamos, portanto, com a metodologia de pesquisa da História Oral, e como oralistas, criamos registros, com a participação indispensável de nossos colaboradores. Criamos fontes que, segundo nossas perspectivas, são historiográficas, entre outras razões, porque dizem "de um tempo, de uma condição, de um espaço, de um modo de existir, de falar, de se portar" (GARNICA, 2012, p. 89), e cuja utilização, no entanto, exige

o reconhecimento da inexistência de uma verdade sólida, inquebrantável, intransponível, definida e definitiva; o choque entre a pluralidade de pontos de vista distintos que essas fontes trazem à tona; a responsabilidade ao costurar, para a pesquisa, essas fontes que lhe dão [ao oralista] uma percepção parcial, mas nem por isso pouco nítida, da realidade em que está mergulhado (GARNICA, 2007, p. 24).

Assumir as narrativas como fundamentais para conhecer algo, como resíduos de enunciação a partir dos quais o pesquisador intencionalmente cria fontes históricas, implica desestabilizar o registro, a interpretação, aceitando a verdade do sujeito que fala sobre aquilo que se pretende conhecer (GARNICA, 2007, p. 31). Uma narrativa, na concepção de Bolívar, traz: “[...] a qualidade estruturada da experiência entendida e vista como um relato; [...] uma particular reconstrução da experiência, por meio da qual e mediante um processo reflexivo, se dá significado ao vivido" (BOLÍVAR, 2002, p. 5), e constitui não só o instrumento para o alcance das experiências, mas é ela própria constituída dessas experiências e constituinte de (novas) vivências.

Ora, podemos dizer que a postura envolvida com a História Oral é genuinamente hermenêutica: o que fascina numa entrevista é a possibilidade de tornar a vivenciar as experiências do outro, a que se tem acesso sabendo compreender as expressões de sua vivência. [...] "Compreender", diz Dilthey, "é reencontrar o eu no tu". É alargar nossos horizontes em relação às possibilidades de vida humana, é vivenciar outras existências (ALBERTI, 2003, p. 2, grifo da autora). 
Em vista disso, nossa ótica esteve voltada para as experiências/vivências por meio das narrativas em variados contextos relacionados aos livros didáticos de Matemática. Para selecionar os sujeitos de nossa pesquisa, procuramos professores em exercício profissional nos anos iniciais do Ensino Fundamental que faziam uso de livros didáticos de Matemática em/para suas aulas. Optamos inicialmente por elaborar e aplicar, em escolas da rede pública e da rede privada da Região Metropolitana de Belo Horizonte, um questionário escrito a esses professores.

Composto por 18 questões, sendo sete delas fechadas, isto é, solicitando apenas marcação de alternativas, e as restantes abertas, esse questionário ${ }^{4}$ possibilitou aos respondentes uma breve interação dissertativa com nosso objeto de estudo, exercendo também a função de preparo para uma futura entrevista daqueles que se dispusessem a concedê-la a nós. Ao final do questionário, anunciamos aos sujeitos nossa intenção de, posteriormente, estabelecermos novos contatos para a realização de entrevistas com maior aprofundamento nas experiências individuais vinculadas aos livros didáticos de Matemática.

Durante o segundo semestre de 2010, conseguimos coletar 89 questionários distribuídos em escolas públicas e particulares. Escolhemos os questionários a serem analisados com base nos seguintes critérios: seus respondentes deveriam ser professores que estivessem em exercício profissional nos anos iniciais do Ensino Fundamental; professores com formação legal para esse exercício, mesmo que em nível de Ensino Médio; e professores que ministrassem aulas de Matemática. A partir daí, obtivemos um grupo de 65 professores, dos quais apenas 32 concordaram com a ideia de nos darem entrevistas, informando seus números de telefone e/ou endereços eletrônicos. $\mathrm{O}$ estudo das respostas desses 32 questionários levou-nos à seleção de 16 professores para a realização das entrevistas. Para essa seleção, priorizamos aqueles que apresentaram as respostas mais longas e melhor desenvolvidas, apesar de o espaço disponibilizado no questionário não favorecer isso. Também levamos em conta, para a seleção dos possíveis colaboradores, aspectos como formação, tempo de atuação docente, tipo de rede de ensino, turnos de trabalho e sexo, tendo em vista nosso interesse

4 As sete questões iniciais, fechadas, focalizaram idade, formação, capacitação docente, tempo de magistério, tipo de rede de ensino de atuação, turnos e disciplinas ministradas, com o intuito de identificarmos, mesmo que de forma abrangente, elementos socioculturais relacionados à vida dos professores. A partir da oitava questão, as perguntas abertas se voltaram para recursos didáticos que os docentes utilizam nas aulas de Matemática, incorporando o livro didático mediante perguntas sobre seu conceito de livro didático de Matemática, qual livro usam, o que gostam e o que mudariam nesse livro e, finalmente, sobre sua participação na escolha desses livros. No caso de resposta afirmativa para essa última questão, indagamos sobre os critérios de seleção utilizados. 
em contemplar uma multiplicidade de dimensões socioculturais relacionadas à nossa investigação.

Depois dos contatos com esses docentes, conseguimos realizar dez entrevistas com professores dos anos iniciais do Ensino Fundamental, que declararam utilizar livros didáticos em suas aulas de Matemática. Foram nossos colaboradores os professores Gislane, Ercivane, Fabiano, Renata, Rosângela, Ana Lúcia, Márcia, Cléia, Vilma e Ana Cristina ${ }^{5}$, que lecionam em escolas das redes municipal, estadual e particular de Belo Horizonte, e que nos concederam seus depoimentos, realizados a partir de um roteiro previamente recebido.

Após a gravação das entrevistas em vídeo, procedemos à degravação ou transcrição das oralidades registradas, procurando fixar o diálogo por meio de caracteres gráficos, o que constituiu um processo demorado e minucioso. Realizamos, posteriormente, a textualização das transcrições, isto é, fizemos uma edição desse material na qual ocultamos tanto as falas da entrevistadora, a primeira autora deste texto, quanto grande parte dos registros próprios da oralidade, na busca por alcançarmos, nas narrativas, os usos dos livros didáticos de Matemática. Porém, cabe salientar que o formato assumido nas textualizações e a forma escolhida para a escrita das mesmas revelam nossa presença nas narrativas, em busca do cumprimento de nossos objetivos.

Nas textualizações, segundo Garnica, "são preenchidas lacunas, reordenadas passagens e minimizados os chamados vícios da oralidade, já que linguagem oral e escrita são formas muito distintas de expressão" (GARNICA, 2007 , p. 247). Segundo o mesmo autor, a textualização tenta preservar o "tom" do depoente, "ainda que este tom já esteja irremediavelmente impregnado, pela própria natureza do processo e pela manipulação do textualizador, dos desejos, das necessidades e dos tons desse agente que toma nas mãos a tarefa de textualizar". Somos conscientes de que "o que foi dito, como foi dito, nas circunstâncias em que foi dito é evanescente, sempre foge, sempre escapa" (GARNICA, 2007, p. 247).

Para textualizar as entrevistas, orientamo-nos pelo tema dos usos do livro didático de Matemática, e como as perguntas buscavam a relação dos colaboradores com o livro didático desde antes de se constituírem docentes dos anos iniciais do Ensino Fundamental, a ordenação cronológica dos fatos narrados pelos professores pareceu-nos oportuna e coerente. Desse modo, nas textualizações, não tivemos a intenção de preservar a organização conferida à entrevista pela transcrição. Para além de uma mera técnica cuja essência está apenas numa preocupação estilística, concordamos com Garnica (2007) que os momentos de degravação e textualização são estratégias de ação metodológica,

5 Esses são os prenomes reais dos entrevistados, cuja divulgação foi por eles autorizada. 
instâncias de familiarização em relação ao que foi narrado e, por isso, "denotam uma forma de conceber conhecimento e implicam, seguramente, uma concepção de História Oral atrelada a uma epistemologia específica" (GARNICA, 2007, p. 56). O conjunto das dez textualizações ${ }^{6}$ constituiu o principal material empírico de nossas análises. Quando nos debruçamos sobre ele, tendo em mente as respostas de nossos entrevistados ao questionário inicial e suas falas nas entrevistas realizadas, gravadas e transcritas, constatamos que muitas práticas dos professores referentes ao uso dos livros didáticos caracterizam essas obras como um recurso relevante na formação docente para o ensino da Matemática, que é visto de forma positiva, mas também percebido com críticas nas narrativas que auscultamos.

\section{Como os livros didáticos de Matemática participam da formação dos professores dos anos iniciais do Ensino Fundamental?}

No que tange aos discursos relativos ao tema da formação de professores, existe, na atualidade, consenso de que não há formação inicial suficiente para o desenvolvimento profissional (NÓVOA, 1992; SANTOS, 1998; PERRENOUD, 2000; CANDAU, 2001), visto que a formação continuada é assumida como fundamental não somente por ter como meta diminuir as lacunas deixadas pela formação inicial, mas por se revelar como uma realidade presente nas escolas. De fato, considera-se que é nesse espaço que os professores se atualizam mutuamente de maneira a desenvolver saberes e conhecimentos mediante trocas de experiências entre pares e grupos atuantes em um mesmo ano e/ou segmento escolar.

As narrativas de nossos colaboradores nos conduziram à apreensão dessa dimensão da formação continuada de professores. Identificamos que as situações de uso dos livros didáticos de Matemática pelos docentes contemplam

6 Nos trabalhos em História Oral, a textualização segue um momento de conferência e legitimação do registro escrito pelos colaboradores da pesquisa e, até por questões jurídicas, é solicitada dos mesmos, após essa checagem, a assinatura de mais um documento. Em nossa pesquisa, esse documento foi uma carta de cessão, pelos colaboradores, dos direitos sobre suas respostas aos questionários, bem como sobre as gravações e textualizações de suas entrevistas. Nesse processo de negociação das textualizações, cabe ressaltar que nenhum de nossos entrevistados alterou significativamente os textos, explicitando que se reconheceram nas falas textualizadas. É importante frisar, também, que as poucas exclusões que fizeram de suas falas nas textualizações ocorreram por não mais se identificarem com o que haviam dito no momento da entrevista, alegando ora que não pensavam mais como antes, ora que se informaram melhor sobre determinados apontamentos. 
tanto estudos dos conteúdos matemáticos e buscas por atividades ou modos de articulação entre os diversos conteúdos quanto trocas entre os professores e/ou profissionais da escola para discussão da adequação de uma obra didática ao ensino de Matemática a ser promovido. Consideramos, assim, a própria seleção das obras didáticas como um momento de formação continuada.

$\mathrm{O}$ uso estrito do livro didático como recurso que atua no processo de formação docente não aparece como novidade no cenário educacional atual, já que, para a produção editorial de um livro didático de Matemática, é usual a elaboração de um livro para o estudante e um livro direcionado especificamente ao professor, com orientações, sugestões e esclarecimentos didático-metodológicos para a aplicação do que é proposto no livro do aluno. Comumente conhecido como "manual do professor", esse material assume formas muito variadas, podendo ser apresentado por meio de inserções acrescentadas às propostas e atividades do livro do aluno ou em um encarte separado, mas sem existência autônoma, pois está claramente referenciado às páginas e atividades do material do aluno. Como comentamos anteriormente, o Programa Nacional do Livro Didático envolve o manual nos critérios eliminatórios comuns a todas as áreas, explicitando entre esses critérios a "observância das características e finalidades específicas do manual do professor e adequação da coleção à linha pedagógica nele apresentada" (BRASIL, 2012, p. 16). Tendo em vista os interesses das editoras em ter suas obras aprovadas pela avaliação do Programa, a presença do manual fica determinada no planejamento e execução editoriais.

Apesar de não nos remetermos diretamente à expressão "manual do professor" em nosso roteiro de entrevista, considerávamos que nossos colaboradores acabariam se referindo a essa publicação ao responderem a algumas de nossas questões. No entanto, chamou nossa atenção o fato de em nenhuma das narrativas termos localizado indicativos explícitos de que os manuais dos livros de Matemática sejam instrumentos de forte contribuição ao trabalho docente. Encontramos, porém, críticas ou sugestões pontuais em relação a esse material nas entrevistas de Ana Cristina e Ercivane, sem que tivéssemos nos referido explicitamente a ele, e menções ao manual na fala do professor Fabiano após, no decorrer da entrevista, termos incluído a expressão "manual do professor" em uma de nossas observações. Assim, percebemos certa indiferença de nossos colaboradores em relação a essa parte das obras didáticas, além de constatarmos que os professores consideram que ele precisa ser reformulado para que cumpra, efetivamente, as atribuições que lhe são propostas pelo PNLD. Nessa direção, coloca-se o comentário de Ana Cristina: "Quando veio um tal de livro do professor, que mudou a maneira de olhar para o livro didático, que vinha dizendo que na página tal você tinha que falar com a criança assim e assim... se eu fosse falar daquele jeito a criança já tinha ido embora; menino é mais 
rápido!" Ana Cristina sugeriu, assim, que alguns manuais não são adequados às práticas docentes quando prescrevem ao docente maneiras de trabalhar essa ou aquela página ou atividade com as crianças. Ela defendeu que as estratégias didáticas devem ser estabelecidas pelos próprios docentes, pois necessariamente abarcam elementos de cada realidade no que diz respeito às crianças, à escola, à comunidade escolar e, evidentemente, ao próprio professor. Essa afirmação da autonomia do professor em relação ao livro didático surgiu também nas falas de outros professores, como Renata, que manifestou sua posição desfavorável ao estabelecimento de formas de trabalhar com as crianças pelo manual do professor. Para ela, "esse negócio fechado, que traz o que você vai ter que trabalhar... é complicado!" Assim, ela se posicionou: "sou eu que estou dentro da sala de aula e preciso dessa oportunidade, preciso folhear o livro, ver o que tem ali e o que é possivel trabalhar com a criança!"

Já Ercivane, apesar de considerar que no manual encontra importantes atividades complementares, enfatizou, igualmente ao professor Fabiano, que esse texto geralmente não é lido por falta de tempo dos docentes. Ercivane chegou a sugerir, em seguida, que as atividades complementares aconselhadas ao professor no manual deveriam vir junto ao livro do aluno. Fabiano explicitou seu gosto por obras "que trazem, junto ao livro do professor, uma explicação dos autores ao lado do exercício."

Entretanto, sinais de participação do livro didático na formação docente para as práticas pedagógicas sem alusão ao manual do professor apareceram quando Fabiano referiu-se ao livro didático como "o recurso que norteia o que é adequado para o professor dar na etapa de cada ano". A atribuição do papel de orientador do currículo escolar de Matemática ao livro didático esteve presente nas narrativas de outras colaboradoras.

Ana Lúcia, por exemplo, ao narrar sobre uma de suas experiências anteriores de docência nos anos iniciais do Ensino Fundamental, referiu-se à existência de certa "insegurança das pessoas com relação à Matemática." Diante disso, ela acreditava que, para o ensino dessa disciplina, o professor "tem que ser mais... duro, tem que seguir todos os passos; tem que se atingir esse e esse objetivo..." E, como, segundo ela, era "assim que os livros trabalhavam" na época, justificou, em parte, a atuação do livro de Matemática em suas aulas "como um suporte, como um aliado, como uma sequência pra gente ter um norte!" Ao discorrer sobre uma experiência recente, a professora reafirmou: "hoje o livro continua sendo um norte, como uma proposta... curricular." Em vez de ir até o documento oficial curricular, ela declarou que recorria ao livro, concluindo: "Portanto, $o$ livro é um instrumento de trabalho, importante." E repetiu: "Eu acho o livro didático um instrumento de trabalho importante, sim!" Contudo, salientou não acreditar na existência de "um livro que ensine a pensar mesmo", o que "torna 
complexa a escolha dos livros!" Ana Lúcia explicou: "Normalmente, a gente acha que está fazendo uma escolha acertada e, na hora que você vai usar o livro, você vê que ele não tem nada a ver com aquele grupo!"

A fala de Ana Lúcia se assemelha ao comentário de Renata que, sorrindo, disse que "um livro didático que tenha tudo nunca vai existir, não tem jeito". Segundo ela, "por mais que um professor tenha planejamento, ele chega na sala de aula e tem sempre uma mudança!... Dando sua aula, muitas vezes, [o professor mesmo] observa que poderia falar sobre a mesma coisa de outra maneira..." Renata vinculou essa ideia ao livro: "A mesma coisa acontece com o livro... se eu gostei de um livro daquele autor hoje; amanhã... Você pode estar pensando de outra maneira! [...] Você vai identificando que o autor ainda poderia ter feito diferente!"

Pareceu-nos relevante que Renata tenha conferido ênfase à participação do livro em seus planejamentos diários e anual: "Se eu não tivesse o livro didático eu ia ficar pulando igual pipoca, sem saber pra onde ir! Por mais que seja só pesquisar no PCN e trazer o concreto pra sala... a gente tem que se virar!" Mesmo que não seja um livro tão bom, um "aspecto importante é que o livro didático foi feito dentro dos Parâmetros Curriculares Nacionais (PCN), então, por pior que ele seja, o que tem ali dá pra te ajudar a montar a aula! [...] então, pra mim, ele é um instrumento muito bacana!" Acrescentou que "o professor que nunca pegou e que não quer pegar no PCN, o livro didático vai orientá-lo pra saber, mais ou menos, o que ele tem que dar em cada série." E concluiu: "Então, o livro é, também, um condutor para o professor, oferecendo um caminho a ele!" Porém, a professora acrescentou: "penso que cabe, também, ao professor, olhar o livro antes de usá-lo!"

Cléia, que valoriza o interesse de seus alunos - "Eu aprendi que a gente aprende aquilo que a gente tem interesse!" -, também explicitou a ideia do livro didático conter a rota a percorrer: "Agora, o livro dá sim, dá o caminho! O livro está centrado no currículo; é importante!" Todavia, essa declaração se fez acompanhar de outros comentários que parecem desestabilizar a centralidade atribuída ao livro didático no traçado do trajeto. Por exemplo, Cléia manifestou sua discordância quanto à sequenciação dos conteúdos proposta pelos livros ao dizer que

O livro está ali bem programado, ele foi construído por alguém que tem conhecimento do currículo! Mas, na minha opinião, o livro não tem a sequência que atende a sequência daquilo que a criança deseja. Aquilo que ela deseja e que você pode colocar pra criança, pensando em compreensão, porque eu não posso querer que uma criança faça uma 
atividade de Matemática sem compreendê-la! [...] na minha opinião, o livro não é pra gente pegar e trabalhar até o final, não! [...] no livro, o que interessa à criança pode estar no conteúdo que está na última página!

Surgem outras observações críticas quanto à potencialidade de o livro didático constituir-se na única ou na principal referência para o desenvolvimento das práticas em relação à Matemática. Márcia remeteu-se à ideia de incompletude dos livros didáticos: "olhamos o livro que mais desperta a curiosidade dos alunos, mas, em sala, a gente tem que complementar com o que falta no livro, porque nem todos são completos." Rosângela reforçou essa perspectiva ao narrar optar por livros que estivessem "dentro da realidade dos meninos, pois não adianta ter um livro que os meninos não vão saber nada do que está falando, se não for da vivência deles..."

Em meio a manifestações favoráveis e contrárias ao livro didático como norteador do currículo, acompanhadas de menções dos professores ao uso de outros materiais para direcionar o trabalho pedagógico com a Matemática, tais como o cronograma anual da escola e um documento curricular específico da área produzido pela Secretaria Municipal de Educação de Belo Horizonte, detectamos, nas narrativas, alusões recorrentes dos entrevistados à busca de subsídios para sua atuação, tanto no que diz respeito ao estudo dos conteúdos quanto à localização de atividades a serem realizadas pelos alunos. Os livros didáticos contribuem para ambas as necessidades, constituindo-se, na fala dos professores, como fonte importante para a formação de um repertório de atividades para os estudantes, ainda que também possam ser considerados limitados em relação a esse papel. Esses posicionamentos se revelam no depoimento de Renata:

Tem hora que o livro não me atender é até bom, porque eu fico buscando alternativas em tudo quanto é lugar. [...] para o professor, o livro é um facilitador (traz conceitos que eu esqueci ou não sei mais, de uma maneira bem mastigada) [...] busco em outros livros: exercícios, atividades diversas e ideias de Para Casa. A verdade é que o professor precisa de um apoio, porque ele não é uma cartola, sempre com uma carta pra tirar da manga!

$\mathrm{Na}$ fala de Gislane, outras palavras indicam ideias semelhantes:

[...] nós, professores, procuramos desafios, alguém que pensou diferente pra não repetir exatamente o que está no livro e ampliar a visão da 
criança! Procuramos e pesquisamos em muitos livros didáticos, porque não é possível um livro didático contemplar tudo! [...] o livro didático dá segurança ao professor, pois ele sabe que se ele tiver uma dúvida, ele vai lá! O livro ajuda a acompanhar o conteúdo.

$\mathrm{Na}$ atualidade, porém, o livro didático tem dividido com a internet o papel de manancial de atividades para os alunos, e alguns professores salientaram isso. Foi o caso de Vilma, que apontou a existência de "muito site bacana com sugestões de atividades, jogos matemáticos e atividades de alfabetização." Ercivane, que também declarou realizar muitas pesquisas na internet, chamou a atenção, assim como outros de nossos colaboradores, para as contribuições, em sua formação, provenientes da interlocução com colegas no dia a dia da escola em que trabalha: "a gente se ajuda muito!"

Fabiano contou que, no início de sua carreira docente, "em termos de conteúdo", pesquisou "muito com professores que via que trabalhavam legal a Matemática". Depois de alguns poucos anos de experiência profissional, esse professor disse que continuava "buscando informações com seus colegas de escola" e sublinhou a ideia de que a formação continuada dos professores acontece na prática em face da realidade estabelecida pelo alunado: "Percebo que é só quando você vai ser professor que você sabe o que precisa, pois a demanda é também dos alunos, das turmas."

Percebemos a valorização, pelos professores, dos encontros informais entre colegas, além das reuniões previamente previstas para discussões pedagógicas, incluindo as várias instâncias de formação continuada oferecidas ora pelas escolas, ora pelas secretarias de educação. Os professores que entrevistamos conferem grande relevância a cursos para a atualização docente. Márcia, por exemplo, levantou que "às vezes, os professores não gostam de participar de cursos, porque eles acham que vão ver tudo o que eles já sabem", mas relatou que buscava aproveitar essas oportunidades, pois, segundo ela, "sempre tem alguma coisa nesses cursos que pode melhorar o trabalho docente."

Os professores enfatizaram, particularmente, a necessidade de se melhorar a formação em Matemática, incluindo-se aí o aprimoramento em relação à metodologia de ensino dessa disciplina, para o professorado que atua nos anos iniciais do Ensino Fundamental. As razões apresentadas por eles para essas reivindicações estão claramente vinculadas às constatações de falhas detectadas ao longo de suas práticas docentes, advindas de um elevado rol de mudanças e recentes estruturações do que se entende hoje como adequado para que se cumpra o ensino de Matemática. Isso foi explicitado, por exemplo, na ponderação trazida por Gislane: "A questão é que quando começou a trabalhar com competências 
e habilidades na Educação, faltou conteúdo nas professoras, principalmente, de Matemática!" Ela indicou o livro de Matemática como um forte aliado para suprimir essa lacuna: "o livro didático começou a ser referência para os professores e não aos alunos, pois ele ajuda a explicar para o professor o conteúdo que ele deveria dar e não sabe."

Nesse contexto em que os docentes prezam o entendimento da Matemática pelo educando, identificamos que o reconhecimento do aluno como centro do processo de ensino e aprendizagem possibilita reflexões de diferentes naturezas por parte dos professores, que pretendem não só ensinar a Matemática, mas também reaprendê-la com vistas à melhoria de suas práticas pedagógicas. Nesse sentido, nossa pesquisa mostra que os livros didáticos, mesmo sendo criticados, são reconhecidos como componentes notáveis na formação dos professores dos anos iniciais do Ensino Fundamental.

\section{Palavras finais}

Retomemos a intenção investigativa que nos mobilizou a escutar narrativas de Gislane, Ercivane, Fabiano, Renata, Rosângela, Ana Lúcia, Márcia, Cléia, Vilma e Ana Cristina, professores que, em 2011, ano de realização das entrevistas, utilizavam livros didáticos como recursos para ministrar suas aulas de Matemática nos anos iniciais do Ensino Fundamental em escolas públicas e particulares. Alicerçadas por aportes teórico-metodológicos da História Oral, buscamos compreender práticas pedagógicas associadas à utilização dos livros didáticos de Matemática a partir de elocuções de professores.

Nossa intenção de apreender práticas por intermédio de narrativas de professores partiu do reconhecimento das peculiaridades das falas, que fazem emergir concepções subsidiadas pelas múltiplas instâncias que circundam e constituem a utilização dos livros didáticos de Matemática. Neste texto, dedicamo-nos a discorrer sobre alguns aspectos que caracterizam o uso dos livros didáticos pelos professores dos anos iniciais como um elemento importante, embora não único, da preparação para a docência em Matemática.

No que diz respeito especificamente à formação matemática de professores polivalentes, Nacarato, Mengali e Passos (2009) discutem os desafios que esses professores enfrentam ao ter que ensinar o que nem sempre aprenderam. Os professores que entrevistamos fazem dos livros didáticos instrumentos para fazer frente a esses desafios, ao mesmo tempo que discordam dos modos como essas obras propõem o ensino. Fica evidente, em diversas narrativas, como 
procuramos mostrar, um descontentamento quanto à abordagem proposta pelos livros. Contudo, como hoje parecem estar eliminadas quaisquer possibilidades de abdicação dos livros didáticos, os professores acabam por fundamentar neles não só as atividades que apresentam a seus alunos, como também seu próprio estudo do conteúdo matemático e, em alguns casos, seu planejamento anual.

Convive, portanto, com as críticas que tecem e a afirmação de seus próprios saberes, sobretudo quanto às suas realidades escolares, o reconhecimento dos professores que ensinam Matemática quanto à importância dos livros didáticos num processo de formação contínua, que, em sua visão, é essencial a seu exercício profissional.

\section{REFERÊNCIAS}

ALBERTI, V. O fascínio do vivido, ou o que atrai na História Oral. Rio de Janeiro: CPDOC, 2003.

BELO HORIZONTE. Secretaria Municipal de Educação. Proposições Curriculares Ensino Fundamental Matemática - Belo Horizonte/MG: SMED, 2010.

BOGDAN, R.; BIKLEN, S. Características da investigação qualitativa. In: Investigação qualitativa em educação: uma introdução à teoria e aos métodos. Porto: Porto Editora, 1994, p. 47-51.

BOLIVAR, A. "De nobis ipsis silemus?": Epistemología de la investigación biográfico-narrativa en educación. Revista Electronica de Investigación Educativa, Mexico, v. 4, n. 1, 2002.

BRASIL. Secretaria de Educação Fundamental. Parâmetros Curriculares Nacionais: Matemática. Brasília: MEC/SEF, 1997.

BRASIL. Secretaria de Educação Básica. Guia de livros didáticos: PNLD 2013: Matemática. Brasília: Ministério da Educação, Secretaria de Educação Básica, 2012.

CANDAU, V. M. Magistério: construção cotidiana. 4. ed. Rio de Janeiro: Vozes, 2001. D’AMBRÓSIO, U. Prefácio. In: BORBA, M. de C.; ARAÚJO; J. de L. (Org.). Pesquisa qualitativa em Educação Matemática. 4. ed. rev. ampl. Belo Horizonte: Autêntica, 2012, p. 11-23.

GARNICA, A. V. M. História Oral em Educação Matemática: outros usos, outros abusos. Guarapuava: Sociedade Brasileira de História da Matemática, 2007. 
GARNICA, A. V. M. Registrar oralidades, analisar narrativas: sobre pressupostos da História Oral em Educação Matemática. Ciências Humanas e Sociais em Revista, v. 32, n. 2, p. 29-42, jul./dez. 2010.

GARNICA, A. V. M. História Oral e Educação Matemática. In: BORBA, M.; ARAÚJO, J. de L. (Org.). Pesquisa qualitativa em Educação Matemática. 4. ed. rev. ampl. Belo Horizonte: Autêntica, 2012, p. 87-109.

MUNAKATA, K. O livro didático como mercadoria. Pro-Posições, Campinas, SP, v. 23, n. 3 (69), p. 51-67, set./dez. 2012.

NACARATO, A. M.; MENGALI, B. L. da S.; PASSOS, C. L. B. A matemática nos anos iniciais do ensino fundamental: tecendo fios do ensinar e do aprender. Belo Horizonte: Autêntica, 2009.

NÓVOA, A. Formação de professores e profissão docente. In: NÓVOA (Org.). Os professores e a sua formação. Lisboa: Publicações Dom Quixote, 1992.

PERRENOUD, P. Pedagogia Diferenciada: das intenções à ação. Porto Alegre: Artmed, 2000.

ROCHA, H. H. P.; SOMOZA, M. Apresentação do dossiê Manuais escolares: múltiplas facetas de um objeto cultural. Pro-Posições, Campinas, SP, v. 23, n. 3 (69), p. 21-31, set./dez. 2012.

SANTOS, L. L. de C. P. Dimensões pedagógicas e políticas da formação contínua. In: VEIGA, I. (Org.). Caminhos da profissionalização do magistério. Campinas: Papirus, 1998.

SILVA, H. da.; BARALDI, I. M.; GARNICA, A. V. M. Sentidos para a pesquisa com narrativas (em Educação Matemática), 2013 (no prelo).

Texto recebido em 13 de novembro de 2013.

Texto aprovado em 08 de dezembro de 2014. 
